\title{
Collaborating in the Francophonie
}

\author{
A shared language can be a powerful asset for collaboration, and \\ can also help build research capacity in developing countries.
}

"Increasingly, research

\section{teams bring together}

individuals from different

disciplines, organizations,

sectors and nations."

Suzanne Fortier, president of Canada's Natural Sciences and Engineering Research Council
IT WAS after a 14-hour workday spent installing scientific instruments around Nyiragongo, an active volcano in the Democratic Republic of Congo, that geophysicist Nicolas d'Oreye met the old man who showed him the true value of his research. At the foot of the volcano, in the city of Goma, the man recounted how he had lost everything in Nyiragongo's last eruption, four years earlier: lava had razed his home and separated him from his family, who were trapped for weeks on the other side of the flow. As the sun began to set, the silhouette of the $3,470 \mathrm{~m}$ high volcano dwarfed the old man's slight frame. At the top of the crater, the magma still glowed red.

For d'Oreye, at the time around $7,000 \mathrm{~km}$ south of his desk at Luxembourg's National Museum of Natural History, the encounter was a stark reminder of the importance of monitoring the volcano. "It made me aware of the human tragedy that everyone here is exposed to on a daily basis," he says. "I cannot abandon the issue."

Nyiragongo is one of the most active and dangerous volcanoes in Africa, and there is still much to be done in terms of surveillance. For this reason d'Oreye and his colleagues set up the GORISK project, which uses both ground sensors and satellite
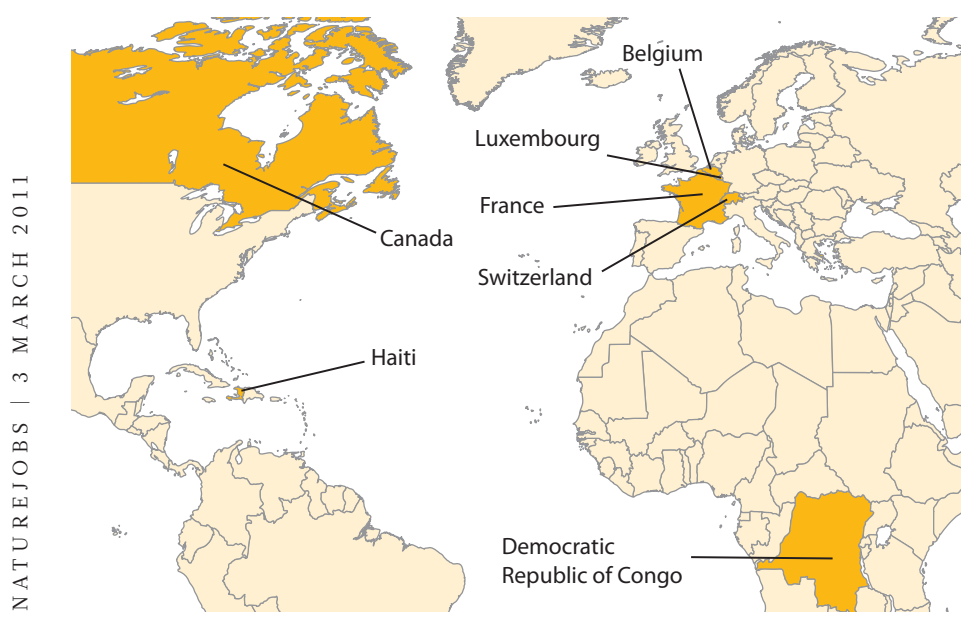

imagery to track deformations in the Earth's crust. The project, which could help predict future eruptions, was launched in 2006. It is a prime example of collaboration between francophone countries. Funded by the National Research Fund (FNR) in Luxembourg and the Belgian Federal Science Policy Office (BelSPO), it brings together experts in geology, geographic information systems (GIS) and hazard assessment from institutes across Luxembourg and Belgium to work with local Congolese scientists.

Research in and around Goma is not easy - the region is one of the most dangerous places on Earth. In addition to the constant threat posed by the volcano to the north, and a lake filled with volatile methane gas to the south (see go.nature.com/gsh $2 \mathrm{xU}$ ), the region is also the epicentre of a longstanding conflict between the Congolese army and rebel militias that has left over five million people dead and millions more displaced.

More than anything, the team has stuck with the project because of the interaction with local residents and researchers along the way. Facilitated by a shared language - the DR Congo is one of twenty francophone countries in Africa - d'Oreye and his collaborators found that the personal connections they made helped to reinforce their common scientific goal.

"Our motivation from the beginning has been to apply science to areas that need it most, in this case a city of a million people in the path of a volcano that is poorly understood and poorly monitored," says d'Oreye.

The GORISK project is just one of thousands of scientific collaborations between funding agencies, universities and research institutes across the French-speaking world. Based on shared language, culture and history, the partnerships are stimulating research in fields from geophysics to quantum computing, while helping to build scientific capacity in developing nations.

"Increasingly, research teams bring together individuals from different disciplines, organizations, sectors and nations," says Suzanne Fortier, president of Canada's Natural Sciences and Engineering Research Council (NSERC). "While language and culture are not, in and of themselves, the principle incentive for partnership building, they are an additional asset [that] helps forge sustainable partnerships," she adds.

\section{A European flavour}

Collaborations are the reality of science in d'Oreye's homeland of Luxembourg because of its small size; with just over half a million people, it must reach out to international partners to boost research capacity and quality. At any one time up to four-fifths of the researchers in Luxembourg are foreign, approximately half of them from French-speaking nations. "Around $80 \%$ of our publications are collaborations," says Carlo Duprel, head of international relations at FNR. "There is a strong focus on collaboration because we need to catch up to international standards."

For example, FNR has teamed up with France's National Centre for Scientific Research (CNRS) to create a streamlined funding mechanism, says Duprel. The system allows researchers from either country to submit a single proposal that is evaluated and, if successful, funded jointly by the two organizations. FNR has also signed up to similar funding collaborations with the Swiss National Fund (SNF) and is exploring opportunities with the French National Research Agency (ANR).

Belgium's National Fund for Scientific Research (F.R.S-FNRS) also finances hundreds of projects within the Francophonie. "We finance international mobility, which means that we enable our researchers to go 


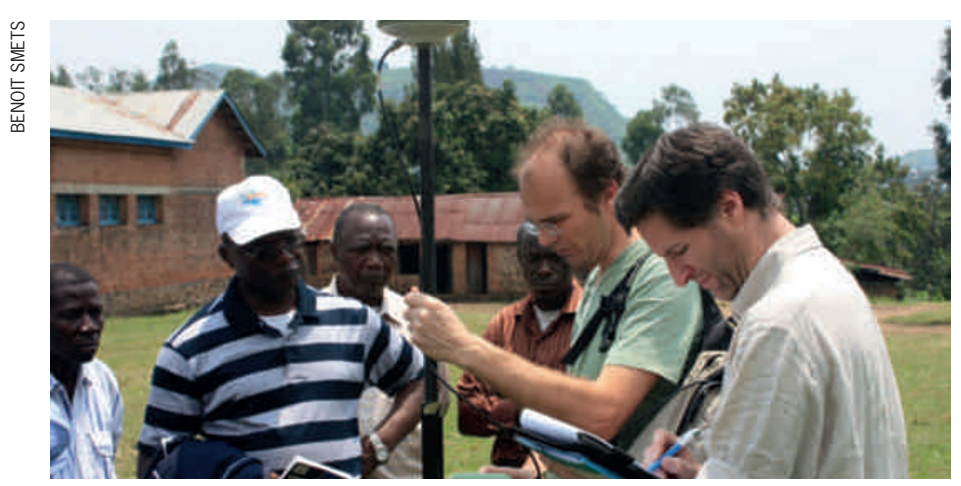

Geophysicist Nicolas d'Oreye (far right) and some of his collaborators prospecting for a new global positioning system (GPS) and seismic station in Bobandana, Democratic Republic of Congo.

to conferences and workshops around the world," says Véronique Halloin, the agency's secretary general.

\section{Across the pond}

The collaborations extend across the Atlantic as well. In 2009, ANR

teamed up with Canada's NSERC to grant around US $\$ 4$ million each year for collaborative projects across a range of fields, including advanced communication technologies, information management and biotechnology. Through one of the projects, the Institute of Quantum Computing (ICQ) at the University of Waterloo in Ontario and its Canadian and French partners are investigating how quantum information technology can benefit information security. "We are seeing a lot of interest in building FranceCanada teams," says NSERC's Fortier. "These teams bring complimentary expertise and strengths."

\section{Crossing the north- south divide}

The Association of Francophone Universities (AUF) is a major vector for collaborations on all continents, operating a massive network of 774 institutions in 90 countries. Every year the association hands out more than 2,000 grants to collaborations between its member countries. In particular, AUF funds a slew of initiatives to support research in francophone countries in the southern hemisphere; for example, it runs 12 virtual campuses in Haiti and funds close to 1,000 students from Africa in PhD and master's programmes through e-learning.

In one of these programmes, Thierry Karsenti from the University of Montreal is collaborating with eight francophone countries in explaining that researchers are free to write-up their work in the language of their choice.

But in many cases collaborating in French can be helpful, especially in developing francophone countries where English is rarely used. "French is either the mother tongue or second language in many of these countries," says Oillo. "It's not a foreign language [like English]."

Beyond the language,

shared culture is also an asset. "Collaborations with the Swiss are very easy," says FNR's Duprel. "Switzerland [like Luxembourg] is a relatively small country but their research has a high impact on their economy and their quality of life."

And the promotion of French as a vehicle for science in and of itself is valuable, according to Pierre Noreau, head of the Francophone Association for Knowledge (Acfas), which is based in Montreal, Canada. "It's not just French for French's sake - it's one of the languages that can help us enrich the way we look at things," he says.

\section{Limits to French}

\section{Changing trends mean that the}

French language has its limits when it comes to research and collaboration. English has become the lingua franca - the working language - of science in recent years, and out of the 3,700 leading journals indexed in Thomson Reuters' Science Citation Index, almost $83 \%$ are published in English, compared to around 3\% in French.

For some countries, such as Luxembourg, this is not a barrier. Most of the day-to-day work at FNR is carried out in French, but the fund issues its official communications in English. "We are used to jumping from one language to another," says Duprel. "If English is the best language to use in a circumstance, we use English."

Researchers at all levels should consider following FNR's example if they plan to make a big impact on the research stage. "If you want to be visible internationally, and if you want access to the scientific community worldwide, you need to publish in English," says Duprel. "That's the way it is."

\section{Breaking down the language barrier}

There are also initiatives in place to help improve access to research published in English. For example, France's National Institute of Health and Medical Research (Inserm), based in Paris, produces Médecinel Sciences, a French-language science magazine that features articles and editorials written by top physicians and researchers. It covers the latest findings in medicine and biology from English-language journals, says Suzy Mouchet, Inserm's head of scientific information and communication, who acts as an adviser for the publication.

"The English language is the [main] language of communication for primary results and research, for example in journals like Nature and Science," says Mouchet. "But there is a place for analytical magazines in other languages such as French to help with the dissemination of information to professors, students and medical practitioners."

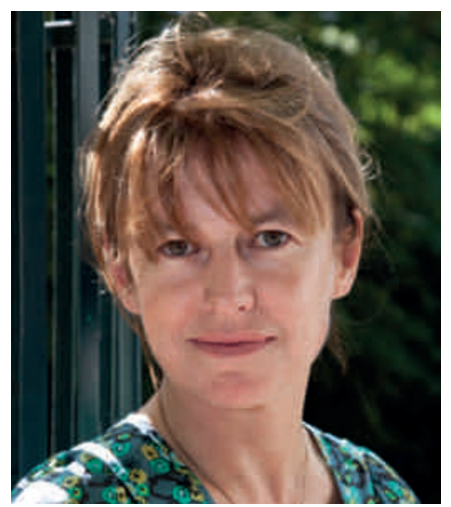

Véronique Halloin: "We enable our researchers to go to conferences and workshops around the world."

Large-scale translation technologies are also gaining ground. WorldWideScience. org is a real-time search and translation tool that offers access to around 80 research databases and information portals from over 70 countries in nine different languages. The tool is based on technology developed in partnership with Microsoft Research.

Such tools could open up international collaboration even further. "In twenty years the translation technologies will be better, [perhaps] even automatic," says Oillo. "Then we may not even need to worry about language." In the meantime, sharing a language will continue to remind scientists such as d'Oreye of the human impact of their research.

Nature editorial staff have no responsibility for content. 


\section{(PPF} FÉDÉRALE DE LAUSANNE
ECOLE POLYTECHNIQUE

\section{Faculty Position in Civil and} Environmental Engineering at Ecole Polytechnique Fédérale de Lausanne (EPFL)

EPFL's School of Architecture, Civil and Environmental Engineering seeks a Tenure-Track Assistant Professor of Geo-Engineering focusing on $\mathrm{CO}_{2}$ Sequestration. It is our intention to hire at the level of Assistant Professor (Tenure Track) but in suitable cases an appointment at the Associate or Full Professor levels will be considered.

The future success of $\mathrm{CO}_{2}$ sequestration in deep, geologically secure formations, either on-shore or offshore, remains uncertain due to numerous technological and scientific challenges. These challenges include an improved understanding of: the physico-mechanical and bio-geochemical processes involved, the roles of geological controls and well technologies on long term storage, methods for locating storage sites and monitoring of their performance, large-scale mathematical modeling combined with field evidence, especially on geochemical interactions. We seek applications from highly qualified scientists and/or engineers committed to a career aiming at excellence in research and teaching. Applications are welcomed from all disciplines pertinent to $\mathrm{CO}_{2}$ sequestration, including, but not limited to, geology, geochemistry, environmental and civil engineering and applied mathematics. The successful applicant will have potential for developing a research profile characterized by novel accomplishments, competitive grant funding and an interdisciplinary, collabo- rative vision. A broad vision of geo-engineering is sought, as is the ability to collaborate across disciplines as customary in the ENAC School at EPFL today.

Successful candidates are expected to initiate independent research programs and participate in undergraduate and graduate teaching. Substantial start-up resources will be available. We offer internationally competitive salaries and benefits.

Applications should include a résumé with a list of publications, a concise statement of research and teaching interests, and the names and addresses (including e-mail) of at least four referees. Applications should be submitted electronically to

http://enac.epfl.ch/page-2114.html by $1^{\text {st }}$ April 2011 when formal screening of applications will begin.

Informal enquiries may be made to:

Professor Andrea Rinaldo andrea.rinaldo@epfl.ch

Additional information about EPFL is available at http://www.epfl.ch, http://enac.epfl.ch.

Ecole polytechnique fédérale de Lausanne is an equal opportunity employer.

Women candidates are particularly encouraged to apply.
“Through our posting

for a post-doc position

at Nature Jobs we have

received messages

from a surprisingly

large number of highly

qualified investigators

from all over the world,

and have been able

to recruit a suitable

candidate. Thank you

very much"

Alberto Sánchez-Fueyo, MD, Hospital Clinic Barcelona/ IDIBAPS, Spain

\section{naturejobs}

with

the latest scientific

news and research, anytime, anywhere

With the new nature.com mobile app you can read scholarly content quickly and comfortably wherever you are

Download now at nature.com/mobileapps
Browse updated news and research each time you access

Read full text articles immediately, or save them for later

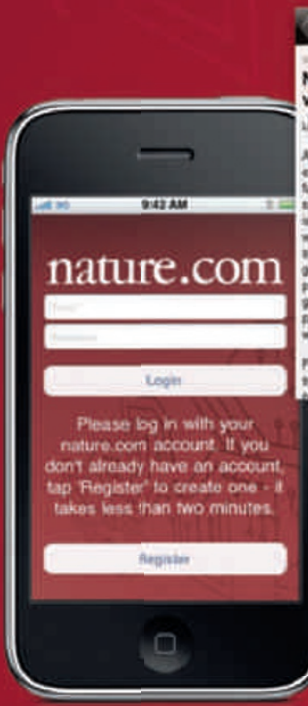

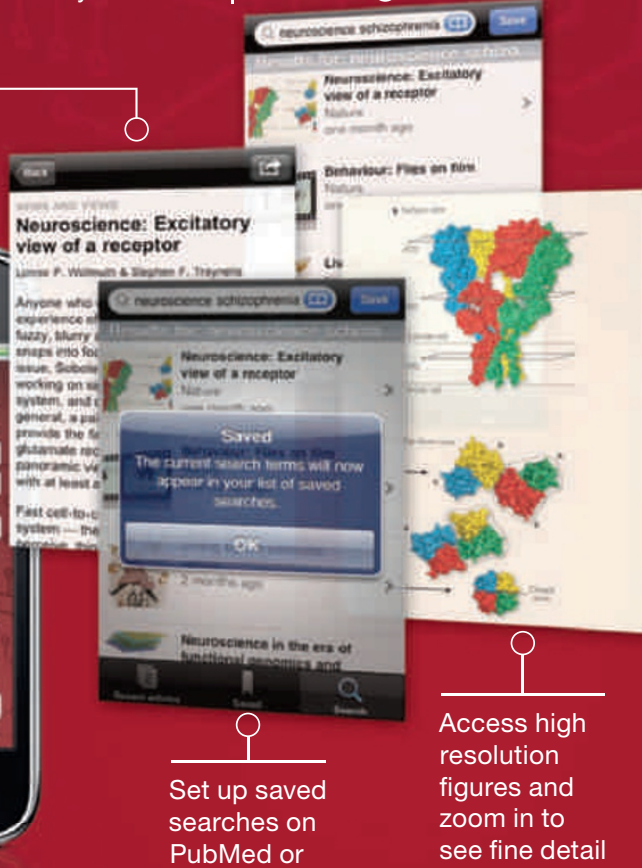


IRCM

INSTITUT DE RECHERCHES CLINIQUES DE MONTRÉAL

Affilié à / Affiliated with Université de Montréal

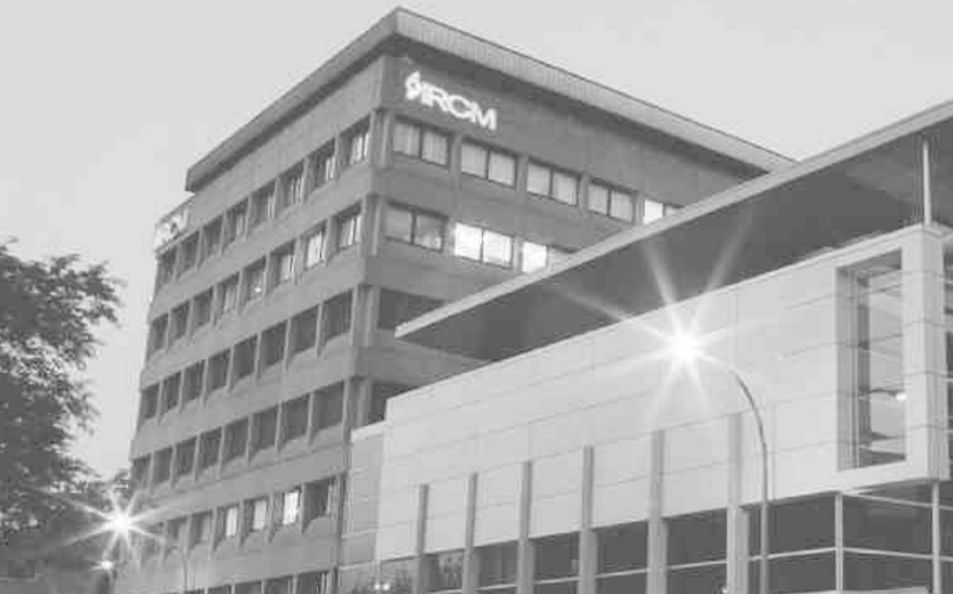

36 UNITÉS DE RECHERCHE - 5 AXES DE RECHERCHE

Biologie intégrative des systèmes et chimie médicinale $•$ Cancer

- Immunité et infections virales $•$ Maladies cardiovasculaires et

métaboliques $•$ Neurobiologie et développement

1 CLINIQUE DE RECHERCHE SPÉCIALISÉE

Hypertension • Diabète $\bullet$ Obésité $\bullet$ Cholestérol
Un institut de recherche biomédicale par excellence à Montréal - Canada

A leading biomedical research institute in Montréal - Canada

\section{NOUS RECRUTONS - NOW RECRUITING}

Directeurs de laboratoire : Cancer $\bullet$ Immunologie •

Biologie computationnelle $\cdot$ Maladies cardiovasculaires

Principal Investigators: Cancer • Immunology •

Computational biology $\bullet$ Cardiovascular diseases

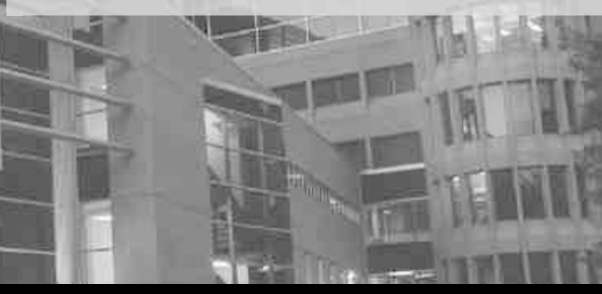

\section{RESEARCH UNITS - 5 RESEARCH PROGRAMS}

Systems biology and medicinal chemistry $\bullet$ Cancer $\bullet$ Immunity and viral infections $\bullet$ Cardiovascular and metabolic diseases $•$ Neurobiology and development

1 SPECIALIZED RESEARCH CLINIC

Hypertension $\cdot$ Diabetes $\cdot$ Obesity $\bullet$ Cholesterol

\section{TENURE-TRACK FACULTY} POSITION

\section{DERARTMENT OF ANATOMY}

\section{$\&$ CELL BIOLOGY}

THE DEPARTMENT OF ANATOMY AND CELL BIOLOGY invites applications for a tenure-track appointment at the rank of Assistant Professor, effective July 1, 2011. Applicants must have postdoctoral training, and a strong research program that complements existing departmental and institutional strengths in the areas of bone biology and bone imaging. Candidates working in the area of bone cell biology would be considered particularly attractive

THE UNIVERSITY is world-renowned for its longitudinal studies of paediatric bone health and more recently for growing expertise in bone imaging with microCT and peripheral quanitative computer tomography (QCT; HR-pQCT). The University of Saskatchewan is also home to the Canadian Light Source (CLS), a world-class synchrotron facility that features a newly constructed biomedical imaging and therapy (BMIT) beamline (http://www.lightsource.ca

THE SUCCESSFUL CANDIDATE will contribute to departmental teaching in one or more subject areas. Departmental courses include gross anatomy, cell biology, imaging and histology as well as courses in the new integrated Biomedical Sciences Platform. The successful candidate will be housed in the state-of-the-art Academic Health Sciences complex to be completed in the summer of 2012

THE UNIVERSITY OF SASKATCHEWAN offers a full range of programs, both academic and professional, in 13 colleges including 7 in the health sciences. For further information about the Department and its programs please go to http://medicine usask.ca/acb.
UNIVERSITY OF SASKATCHEWAN

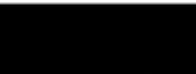

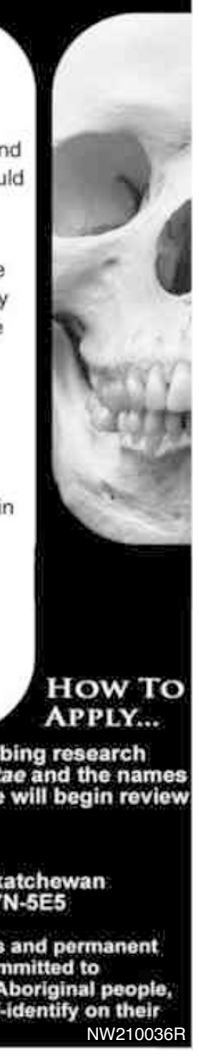

INRS is one of Canada's leading research universities that brings together some 150 research professors in its four research centers located in Montreal, Quebec City, Laval, and Varennes. Conducting applied and fundamental research essential to the advancement of science in Quebec, as well as at the international level, INRS plays a critical role in finding solutions to problems facing our society.

The Énergie Matériaux Télécommunications Centre seeks to fill a tenure-track position of

\section{PROFESSOR-RESEARCHER IN ELECTROCHEMISTRY AND ELECTROCATALYSIS APPLIED TO ENERGY RELATED ISSUES}

The complete position description and modalities of application are available on our Web site in the section: Emplois et stages.
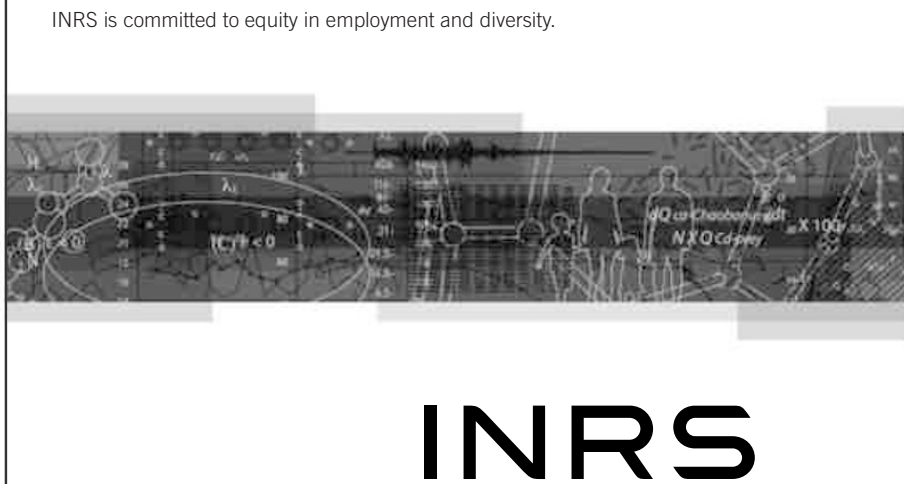

W W W. INRS. CA

Université d'avant-garde 


\section{Unil}

UNIL | Université de Lausanne

THE FACULTY OF BIOLOGYAND MEDICINE OF THE UNIVERSITY OF LAUSANNE, SWITZERLAND INVITES APPLICATIONS FOR A POSITION OF

\section{FULL PROFESSOR \\ DIRECTOR OF THE LUDWIG CENTER FOR CANCER RESEARCH OF THE UNIVERSITY OF LAUSANNE}

This center (LICR@UNIL, www.unil.ch/licr), representing a new forma collaboration between the Ludwig Institute for Cancer Research and UNIL, will be based at the University's hospital and biomedical campuses (CHUV and Epalinges). The focus will be on basic, translational, and clinical cancer research, involving current Ludwig-supported faculty with expertise in tumor immuno-biology and immunotherapy as well as future to-be-appointed faculty focused on other aspects of tumor biology, cancer genetics and experimental therapeutics.

The Director is anticipated to be an accomplished mid-career cancer scientis with the ability to lead LICR@UNIL as well as attract and mentor new faculty. The Director will also contribute to new developments including the establishment of a new Department of Oncology at CHUV/UNIL, and of an integrated regional cancer center in conjunction with the Swiss Institute of Experimental Cancer Research (ISREC) and its parent institution, the Swiss Federal Institute of Technology Lausanne (EPFL).

The operations of the Ludwig Center for Cancer Research will be funded by annual core support from the Ludwig Institute and from UNIL, complemented by support from philanthropic sources, and via Swiss and EU grant mechanisms. Generous support will be available to partially support the Director's research activities.

The successful candidate will have a personal research program focused on mechanisms of cancer with a track record of success and an articulated vision for the future, not only for her/his personal research group, but also for the Ludwig Center and its involvement (along with the parent Ludwig Institute) in developing world-class cancer research in Lausanne.

Proficiency in French is not a prerequisite, although a willingness to become so is anticipated.

Further information may be obtained from Prof. Patrick Franciol (patrick.francioli@unil.ch), chair of the search committee. Confidentiality is guaranteed.

Applicants should send their curriculum vitae, a list of publications in which the five most significant ones are identified, a summary of the past, present and future research program, and at least three names of reference by May $15^{\text {th }}, 201$ for the attention of Prof. Patrick Francioli, Dean of the Faculty of Biology and Medicine, rue du Bugnon 21, CH-1011 Lausanne, Switzerland.

\section{$\therefore \rightarrow$ Ex

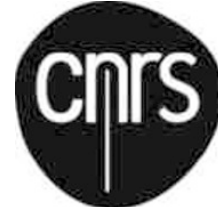 \\ Institut de Moléculaire et Cellulaire, 20 $\because$ Cellulaire,
Sophia-Antipolis,
France}

Our research group has been recently awarded an ERC advanced grant. Through this prestigious program, we are seeking candidates for post doctoral, PhD, and technician positions. Field: Remodeling of cellular membranes and sensors of membrane curvature. Approaches: biochemistry, cell biology and molecular dynamics.

See: www.ipmc.cnrs.fr/?page=antonny.

Contact: antonny@ipmc.cnrs.fr

\section{Institut Pasteur}

\section{COMPUTER BIOLOGIST AND HEAD OF SCIENTIFIC INFORMATION DIVISION}

The Institut Pasteur, a leading center for biomedical research focusing on infectious diseases, neurosciences, developmental biology, immunology and structural biology, is seeking to strengthen its computer biology capacity within a new Direction for Information Systems. An important step in this process will be the recruitment of a Head of the Computer Biology Division, who will take overall responsibility for the management and development of several informatics platforms specializing in genomic analysis, data banks, imaging informatics, and software development, and will also lead an independent research group in bioinformatics, integrative biology, systems biology, modelling or imaging. The position is open to leading computer biologists who wish to pursue their own research programme while developing the informatics resources used by scientists throughout the Paris campus of the institute.

The Application should comprise the following (in order) in a single pdf file:

1. A brief introductory letter explaining why the candidate wishes to join the Institut Pasteur

2. A Curriculum Vitae and a full publication list.

3. A description of past and present research activities and computer biology and management experience (up to 8 pages with 1.5 spacing).

4. The proposed research project (up to 5 pages with 1.5 spacing).

5. The names of 3 computer biologists from whom letters of recommendation can be sought.

The completed application should be sent by E-mail to applyDIS@pasteur.fr by April 30, 2011.

W210273R

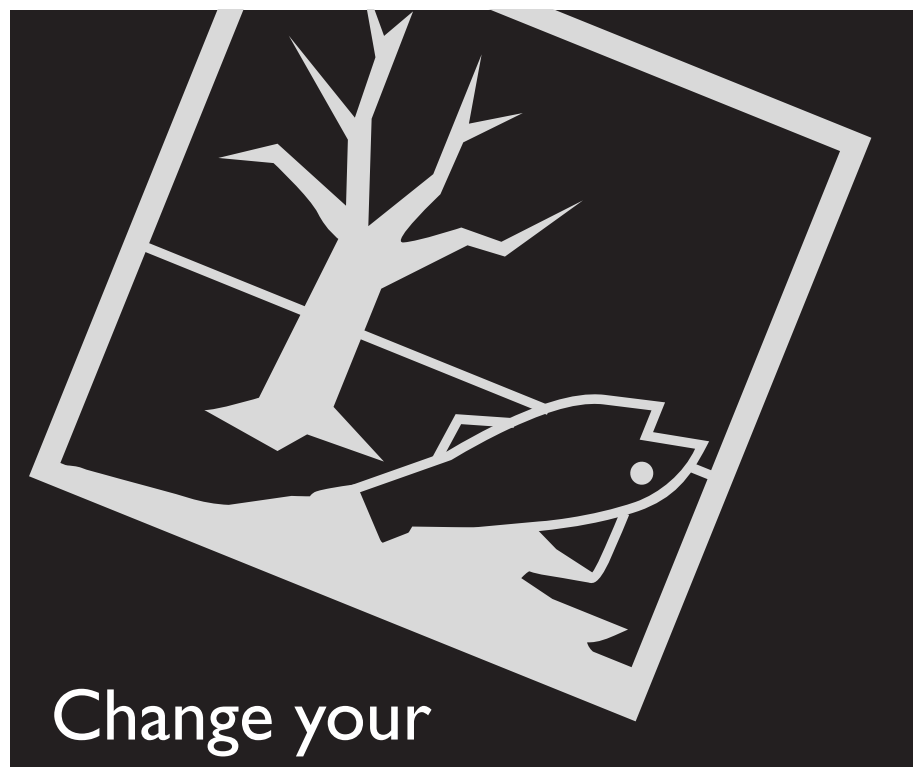

environment. Find

jobs where you'll

make a difference

naturejobs 


\section{in Luxembourg.}

\section{See what's behind it.}

ר PEARL

LUXEMBOURG'S RESEARCH PROGRAMME FOR

INTERNATIONALLY RECOGNISED SENIOR RESEARCHERS

We give you the opportunity to transfer your research programme to a public-sector research institution in Luxembourg and thus to strengthen Luxembourg's research priorities and accelerate their development. Funding: $3-5 \mathrm{M} €$. The call is open all year.

\section{do ATTRACT}

LUXEMBOURG 'S RESEARCH PROGRAMME FOR OUTSTANDING YOUNG RESEARCHERS FROM ALL OVER THE WORLD

We help you to set up an independent research team within a public-sector research institution in Luxembourg. The innovation of your project as well as its high scientific quality should enhance Luxembourg's position in the international world of R\&D. Funding up to $1.5 \mathrm{M} €$.

The $6^{\text {th }}$ ATTRACT Call will be launched in December 2011.

More information about ATTRACT and PEARL as well as the other funding opportunities offered by the National Research Fund Luxembourg can be found on the FNR's website.

Go and see what's behind on www.fnr.lu
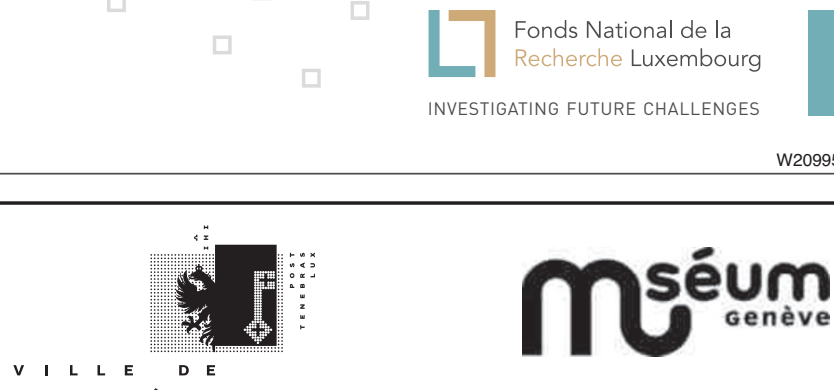

La Ville de Genève recrute le-la directeur-directrice

du Muséum d'histoire naturelle et de sa filiale le Musée d'histoire des sciences

CV et lettre de motivation à l'adresse suivante:

Direction du Département de la culture

Route de Malagnou 19

Case postale 9 - 1211 Genève 17

Clôture des candidatures : 1er avril 2011

Annonce détaillée sur le site emploi de la Ville de Genève www.ville-ge.ch

Contact : Danielle Decrouez, directrice, +4122 / 4186321

danielle.decrouez@ville-ge.ch

The CE.R.I.E.S. Research Award of $40,000 €$ is intended to honor a scientific researcher with a proven track record in fundamental or clinical research work, for a one year period, on the subject of:

\section{PHYSIOLOGY OR BIOLOGY OF HEALTHY SKIN AND/OR ITS REACTIONS TO ENVIRONMENTAL FACTORS}

The awardee will be selected by an international jury consisting of the members of the Scientific Advisory Board of the CE.R.I.E.S.

Previous CE.R.I.E.S. Research Award Winners :

2011 To be determined

2010 Howard Y. Chang, M.D., Ph.D., Stanford, USA

2009 Sabine Werner, Ph.D., Zurich, Switzerland

2008 Paul A. Khavari, M.D., Ph.D., Stanford, USA

2007 Richard L. Gallo, M.D., Ph.D., San Diego, USA

2006 Irwin Mc Lean, Ph.D., DSc, FRSE, Dundee, Scotland, UK

2005 Masayuki Amagai, M.D, Ph.D, Tokyo, Japan

2004 Thomas Schwarz, M.D. Kiel, Germany

2003 Angela M. Christiano, Ph.D., New York, USA

2002 Dennis R. Roop, Ph.D., Houston, USA

2001 Fiona M. Watt, D. Phil., London, UK

2000 Michael Karin, Ph.D., San Diego, USA

1999 Jonathan Rees, M.D., Edinburgh, UK

1998 Jean Krutmann, M.D., Düsseldorf, Germany

1997 Jens-Michael Schröder, Ph.D., Kiel, Germany

1996 Akira Takashima, M.D., Ph.D., Texas, USA

Deadline for applications: June 3, 2011

Requests for application forms must be addressed to:

www.ceries.com

CE.R.I.E.S

\section{CHANEL}

RECHERCHE ET TECHNOLOGIE RESEARCH AND TECHNOLOGY 